\title{
Introducing a Novel Revenue-Sharing Contract in Media Supply Chain Management using Data Mining and Multi-Criteria Decision-Making Methods
}

\section{Mohammad Alipour-Vaezi}

University of Tehran College of Engineering

Amir Aghsami

KNTU: KN Toosi University of Technology

Masoud Rabbani ( $\nabla$ mrabani@ut.ac.ir)

University of Tehran College of Engineering https://orcid.org/0000-0001-8756-4922

\section{Research Article}

Keywords: Revenue-sharing coordination contract, media supply chain management, text mining, sentiment analysis, best worst method, fuzzy DEMATEL

Posted Date: May 24th, 2021

DOI: https://doi.org/10.21203/rs.3.rs-325373/v1

License: (c) (i) This work is licensed under a Creative Commons Attribution 4.0 International License. Read Full License

Version of Record: A version of this preprint was published at Soft Computing on January 9th, 2022. See the published version at https://doi.org/10.1007/s00500-021-06609-0. 


\title{
Introducing a Novel Revenue-Sharing Contract in Media Supply Chain Management using Data Mining and Multi-Criteria Decision-Making Methods
}

\author{
Mohammad Alipour-Vaezi ${ }^{\mathrm{a}}$, Amir Aghsami ${ }^{\mathrm{a}, \mathrm{b}}$, Masoud Rabbani ${ }^{\mathrm{a}^{*}}$ \\ ${ }^{a}$ School of Industrial \& Systems Engineering, College of Engineering, University of Tehran, Tehran, Iran \\ Tel.: +982188021067 \\ Fax: +98 2188013102 \\ E-mail: Mohammad.alipour@ut.ac.ir \\ E-mail: $\underline{\text { a.aghsami@ut.ac.ir }}$ \\ E-mail: mrabani@ut.ac.ir \\ *Corresponding Author
}

${ }^{\mathrm{b}}$ School of Industrial Engineering, K. N. Toosi University of Technology, Tehran, Iran

Mohammad Alipour-Vaezi: http://orcid.org/0000-0002-7529-1848

Amir Aghsami: http://orcid.org/0000-0003-0175-2979

Masoud Rabbani: http://orcid.org/0000-0001-8756-4922 


\begin{abstract}
In recent years, we have observed stunning advances in supply chain coordination. But despite all these scientific methods, some of the businesses are still coordinating traditionally. Media supply chain, and above all its components, the cinema industry has been coordinated traditionally for years. One of the boldest problems in the media supply chain is wage determination in the cinema industry, which in it the actor's efficiency or deficiency is not considered. It means the success or failure of the movie is nothing to do with the actor's revenue. To address this problem, this article proposes a novel revenue-sharing coordination contract that benefits from text mining and the best-worst method. We aim to determine a fair share of profit or loss of a movie for each of its actors based on their performance and efficiency on the success or failure of the project. One of the latest movies is considered as a case study, and its lead actor's wage for this movie is determined under this contract. The sentiment analysis technique investigated the viewers' opinions about the movie and the actor's performance. Since the reviewers mainly are the people who have no expertise in cinematography, they cannot discern the influence of other participants on the actor's performance. So the proposed method used experts' opinions through the fuzzy DEMATEL method to consider the overlapping effect besides enhancing the validity of the reviewers' opinions.
\end{abstract}

Keywords: Revenue-sharing coordination contract; media supply chain management; text mining; sentiment analysis; best worst method; fuzzy DEMATEL

\title{
Introduction
}

Despite the advancement of human science in supply chain management, many businesses are still run traditionally, especially those operating in the media field. For example, we can refer to the cinema industry. There is no scientific or fair way to pay practitioners, especially the actors and actresses who play roles in a filmmaking project. The question that arises here is whether a method can be devised that equates the wage of each actor to the efficiency of his activity on the product, fairly and based on the viewer's opinion (consumer)? In this study, we tried to answer this question.

All members of a supply chain (SC) are linked to each other. Their influence on each other performance is undeniable. It's worth saying that a lack of coordination in the system between its actors usually causes uncertainties. These uncertainties are particularly tangible in cases such as wages and the lead times for receiving a product. As you may know, SCs are defined by a variety of activities and different actors (disparate but interdependent members). If any system wants to reach its objectives, it seems reasonable that individuals might align their goals with those of the organization(system). With this in mind, coordination between activities and actors is necessary to coordinate individual objectives with SC global goals to make optimal performance more reachable.

Contracts have been used as a tool for greater coordination between two or more independent partners (manufacturer, retailer, supplier, etc.) for so long. The classic revenue-sharing coordination contract addresses the occasion the retailer is reluctant to raise its service level, especially in uncertain situations (due to the risk of excess inventory), thereby reducing the possibility of increased shortages and reduced SC total profits. The revenue-sharing contract helps both retailers and suppliers to cover this drawback. Under these coordination contracts, the retailer offers the supplier less than the 
wholesale price for the purchase of each product. Instead, the retailer shares revenue and profit from the sale with the original supplier. (Tsao \& Lee, 2020)

Wage determination (WD) has a bold influence on SC's coordination. But despite all the methods for coordinating the SC, including the coordination contracts, never in any industry, WD was based on efficiency. In this article, we proposed a novel revenue-sharing contract based on fuzzy DEMATEL, text mining (TM), and the best-worst method (BWM) for media SC coordination. Fig. 1 shows the contents of this article.

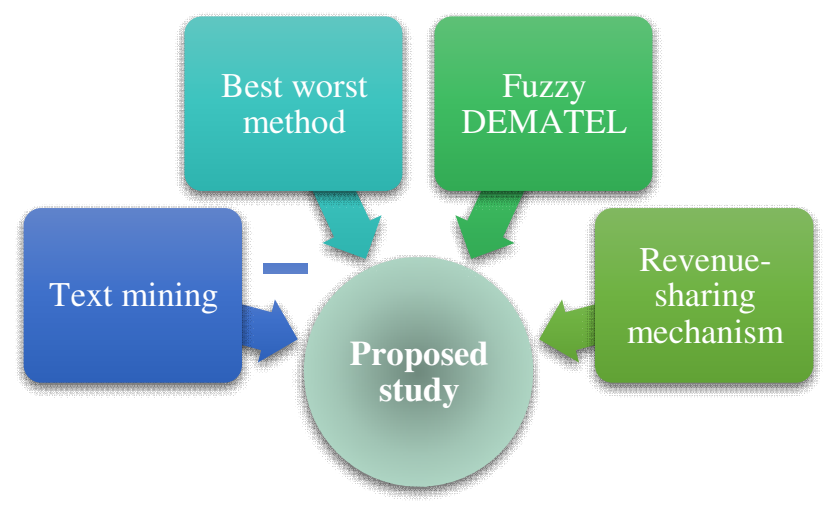

Fig. 1 Summary of the article

It's worth noting that this article's findings can be used in any industry for fair WD and revenuesharing. The reason that in this article, the cinema industry has been considered as the case study is that from the advent of the camera until now, no scientific method is applied in media SC management for fair WD. So the proposed method is so much needed in there.

The rest of the article is organized as follows. Reviewed articles are reported and classified into two categories in section 2: revenue-sharing contract and TM \& sentiment analysis. Also, a comprehensive literature review table and significant research gap are proposed in this very section. Section 3 describes the problem and our two-stage methodology. Each stage's steps are explained clearly. In stage 4, for better understanding the proposed methodology, a real-life case study has been investigated. Section 5 has been dedicated to Sensitivity analysis and discussion, which can give valuable managerial insights. In the sixth stage, a brief conclusion has been conducted that finalized paper.

\section{Literature review}

The vital role of coordination in SC management is not covered to anyone. In this section, a review of several important articles that examined coordination contracts will be proposed. There are many worthy studies about classic coordination contracts (such as (Cachon \& Lariviere, 2005; Lariviere, 1999; Ma, Gao, Wang, \& Li, 2020; Tsay, Nahmias, \& Agrawal, 1999; Wang, Ding, Chen, \& Mu, 2020)) that the readers can use to find more information about coordination contracts.

For better comprehension, reviewed articles are sorted into two main groups: revenue-sharing contracts and Social media TDM and sentiment analysis. 


\subsection{Revenue-sharing contract}

In Hsueh (2014) research, the author aimed to integrate corporate social responsibility with the SC's coordination. For this cause, a new revenue-sharing contract was introduced in the two-echelon SC. For determining the optimal corporate responsibility investment, a mathematical model has been proposed by researchers. Arani, Rabbani, and Rafiei (2016) aimed to cover the flaws in classic coordination contracts, integrated a European call option contract with a revenue-sharing contract. The authors modeled their novel method through a game-theoretic technique that considers and tests different scenarios which the retailer or manufacturer may cope. Liang, Xie, Liu, and Xia (2017) investigated the revenue-sharing mechanism along with the aftermarket service of wind turbines in a closed-loop supply chain. Hu and Feng (2017) Investigated the optimization and coordination of an SC consisting of one supplier and one buyer. They modeled the mentioned SC by revenue-sharing contract and service requirement under an uncertain situation. Benefiting the revenue-sharing coordination contract, Yan, Wu, Ye, and Zhang (2017) coordinates a three echelon fresh agricultural product supply chain that runs through the internet of things. Raza (2018) proposed a new quantitative model that discussed joint pricing and socially responsible investments. Demand has been investigated in both stochastic and deterministic scenarios. The game-theoretic approach has been used in this article to analyze the decentralized, centralized, and agreement based on revenue-sharing coordination contracts. According to the enormous growth of e-commerce, Wei, Li, Gou, and Huo (2019) designed a model based on both revenue-sharing and cooperative investment contracts. Zhao, Chen, and Gong (2019) proposed a conditional probability of the market situation. Authors considering an SC including two retailers(downstream) and a mutual manufacturer (upstream) used revenue-sharing coordination contracts for information sharing. T. Li, Zhang, Zhao, and Liu (2019) used both revenue-sharing and cost-sharing coordination contracts for investigating the impact factor on carbon emission reduction and profitability. Xia, Jiang, Wang, and Zhang (2019) proposed a framework for the revenue-sharing mechanism among an airline and a high-speed rail operator. Various situations have been considered in their research. The results show if the high-speed rail operator is social welfare-oriented or in the multi-airport system, the airlines are a monopoly, the revenue-sharing coordination contract is more reachable. Considering government subsidy and demands' uncertainties Lingcheng, Zhenning, Jiaping, Jing, and Yuping (2019) proposed a revenue-sharing that coordinates upstream and downstream firms and therefore solves the problem of power grid-connection. Liu, Wang, Liu, and Kong (2019) proposed an integrated revenue-sharing and service cost allocation contract for the port service chain coordination. Due regard to uncertainties, Aghajani, Torabi, and Heydari (2020) proposed a mixed possibilistic-stochastic model that integrated a two-period option contract. The essence of their work can be described as supplier selection and inventory prepositioning. They defined a two-stage scenario as the foundation of their model. In the first stage, the optimal supplier is selected and in the second stage, the decision on when and how much to use is made. Panja and Mondal (2020) analyzed two game-theoretic models in a two-layer single manufacturer single retailer green SC. In the first model, market demand is dependent on the green degree of product and the selling price. In the second model, demand is dependent on the credit period that retailer offered, in addition to the green degree of product and selling price. Considering a decentralized SC including one retailer and one manufacturer, Tsao and Lee (2020) determined how revenue-sharing coordination contracts affect decision-making and profits. Canbulut, Köse, and Arik (2021) addressed revenue-sharing coordination contracts as two-person non-constant sum games that each one wants to maximize their profit; So in a supply chine coordinated with a revenue-sharing contract, the supplier determines wholesale price 
which retailer respond with revenue-sharing rate. In their study, the profit function of the supply chain actors has calculated using game theory.

\subsection{Text mining \& sentiment analysis}

Nisa and Qamar (2015) benefited from TM for web services classification and determining key concepts from textual data in the web domain. J. Li, Fong, Zhuang, and Khoury (2016) benefited from hierarchical classification (several classification models and three filters) as TM techniques for online news sentiments analysis. Araque, Corcuera-Platas, Sánchez-Rada, and Iglesias (2017) enhanced the ensemble classification algorithms for sentiment analysis by deep and surface features integration. Amrit, Paauw, Aly, and Lavric (2017) applied TM to identify child abuse. Using a massive dataset related to children's health, they implementing machine learning methods for their research. Monkman, Kaiser, and Hyder (2018) used a TM method in social media for information gathering about wildlife recreation activity. They used an automated scraping method for mining the generated data(content) by online users. Based on TM capabilities, Yu and Guo (2018) designed a model composed of domain dictionary construction, market convergence time calculation, and dimensionality reduction, integrating semantic analysis for news analysis to predict the medical material price. Fu, Liu, and Chang (2018) introduced a new data-driven MCDM method in an evidential reasoning platform. The diagnosis of thyroid cancer is the perfect application of their model and study it, also generating data-driven diagnostic results. Serna and Gasparovic (2018) tried to investigate the tourists' satisfaction with their used transportation model. For this reason, they applied a TM method to assess the tourist's opinion about success factors. Their study shows the vital role of social media data mining in transport and tourism planning. Ismail, Belkhouche, and Zaki (2018) used a fuzzy thesaurus for sentiment analysis and sentient replacement in Twitter for the dimensionality of the feature space reduction. Their method is completely domain-independent. Greco and Polli (2019) proposed their research on emotional text mining(ETM) application on brand management based on a bottom-up technique which is an approach for classification of unstructured data for identification of social media users' sentiment about a subject. Chen, Lee, and Chen (2019) explored social media to analyze the Military life PTT board of Taiwan's largest online forum sentiment using deep learning. Pejic-Bach, Bertoncel, Meško, and Krstić (2020) used the TM technique for investigating job advertisements in industry 4.0. Tan et al. (2020) presented a learning method according to the aspect categories and the aspect terms relation can learn aspect embedding. The objective is to address the relation between the two subtasks of aspect-based sentiment analysis(ABSA): aspect category sentiment analysis (ACSA) and aspect term sentiment analysis (ATSA). Ye and Lee (2020) used TM to analyze the customers' sentiment tendency over time. Their three-step method is commenced with a model for feature words extraction and leads to the second step which is converting costumers' reviews into a sentiment graph. The last step summarizes the reviews that will divulge the customers' tendency. 
Table 1. Summary of the key related researches

\begin{tabular}{|c|c|c|c|c|c|c|c|c|}
\hline \multirow{2}{*}{ Reference } & \multicolumn{2}{|c|}{$\begin{array}{c}\text { Coordination } \\
\text { contract }\end{array}$} & \multicolumn{2}{|c|}{ Uncertainty } & \multirow{2}{*}{ TDM } & \multirow{2}{*}{ MCDM } & \multirow{2}{*}{$\begin{array}{l}\text { Media SC } \\
\text { platform }\end{array}$} & \multirow{2}{*}{ Description } \\
\hline & $\begin{array}{l}\text { Revenue- } \\
\text { sharing }\end{array}$ & Mixed & Fuzzy & Stochastic & & & & \\
\hline (Hsueh, 2014) & $\bullet$ & & & & & & & $\begin{array}{l}\text { A mathematical model proposed for corporative social responsibility } \\
\text { in a two-stage SC. }\end{array}$ \\
\hline $\begin{array}{l}\text { (Arani et al., } \\
\text { 2016) }\end{array}$ & & • & & & & & & $\begin{array}{l}\text { A Stackelberg game is used for the proposed model in a real-life } \\
\text { fashion SC. }\end{array}$ \\
\hline $\begin{array}{l}\text { (Hu \& Feng, } \\
\text { 2017) }\end{array}$ & • & & $\bullet$ & & & & & $\begin{array}{l}\text { This article investigates the optimization and coordination of a single } \\
\text { supplier single buyer SC along with the service requirement. }\end{array}$ \\
\hline (Raza, 2018) & - & & & $\bullet$ & & & & $\begin{array}{l}\text { The authors proposed a model for pricing inventory and corporate } \\
\text { social responsibility investment. }\end{array}$ \\
\hline $\begin{array}{l}\text { (Lingcheng et } \\
\text { al., 2019) }\end{array}$ & $\bullet$ & & & & & & & $\begin{array}{l}\text { The essence of this study is renewable energy power pricing under } \\
\text { uncertain supply and demand. }\end{array}$ \\
\hline $\begin{array}{l}\text { (Zhao et al., } \\
\text { 2019) }\end{array}$ & $\bullet$ & & & • & & & & $\begin{array}{l}\text { Revenue-sharing is used for coordinating the SC to information } \\
\text { sharing. }\end{array}$ \\
\hline $\begin{array}{c}\text { (Panja \& } \\
\text { Mondal, 2020) }\end{array}$ & $\bullet$ & & & & & & & $\begin{array}{l}\text { Two game-theoretic models discussed: demand is dependent on } \\
\text { selling price and green degree of product or is dependent on the credit } \\
\text { period offered by retailer too. }\end{array}$ \\
\hline $\begin{array}{l}\text { (Tsao \& Lee, } \\
\text { 2020) }\end{array}$ & $\bullet$ & & $\bullet$ & & & & & $\begin{array}{l}\text { Considers a decentralized SC, which in its demand is under uncertain } \\
\text { condition and incorporated revenue-sharing policy into their models. }\end{array}$ \\
\hline This study & - & & $\bullet$ & & • & $\bullet$ & $\bullet$ & $\begin{array}{l}\text { The application of a novel revenue-sharing coordination contract in } \\
\text { the media SC has been discussed using BWM, TDM \& fuzzy } \\
\text { DEMATEL methods. }\end{array}$ \\
\hline
\end{tabular}




\subsection{Research gap}

Based on the presented literature review, the following research gaps are identified:

- There are only a few articles that used data mining methods in the coordination contracts platform. However, logically it's necessary for the best results.

- We found no article that benefits from MCDM methods along with data mining techniques for determining the revenue fraction in the revenue-sharing coordination contracts.

- No article uses the revenue-sharing contract for determining the wages of project employees according to quality instead of quantity.

- All three TDM, fuzzy DEMATEL, and BWM methods are relatively incipient. Therefore, there are only a few articles that used this novel technique.

This article covers all of the mentioned gaps by proposing a novel revenue-sharing coordination contract that investigates fair WD in the media SC that uses the TDM-fuzzy DEMATEL-BWM hybrid method for this reason.

\section{Problem description and methodology}

In the last decade, numerous valuable papers have been proposed to coordinate the SC's actors, especially employing coordination contracts. Despite all these researches, many businesses are still coordinated traditionally (if there is any coordination between SC actors). There are lots of businesses that use unscientific methods because there is no proper coordination of WD. These methods almost always lead to injustice.

We believe that in WD, it's not fair to consider quantity instead of quality and effectiveness. So, it seems more reasonable to determine the effectiveness of each employee, and based on this factor, use a revenue-sharing contract that determines their share from the profit. In the WD, it's more professional to use consumers' opinions about the success and failure factors of the product.

All the mentioned problems in previous paragraphs are easily eliminated by this novel proposed methodology. By applying this contract, all members of the SC will share in the profits and losses fairly, which will enhance the organization's excellence and resilience.

As mentioned before, one of the best options for applying this coordination contract is businesses that run on the media platform, e.g. the cinema industry. There is no applied scientific way in the cinema industry for coordinating the participants of a movie-making project and no fair method for determining their wages.

In order to make the participants' wages fairer, it's needed to be determined how much they affect the success or failure of the film. In the first stage of the methodology, each participants' fraction of revenue-sharing is calculated by determining the effect of his role in the film and his efficiency in that role.

Benefiting the social media environment and employing TDM, we can obtain the efficiency degree of each role in the success or failure of the movie from comments of people about the movie, which is reflecting their sentiments. On the other hand, based on the expert's opinion and using a BWM method, the sole efficiency degree of each actor can be obtained. In more accurate words, in the TDM step, we understand the efficiency of each role in the success or failure of the project. After that, in the BWM 
step, we figure out that in success or failure of that specific role, how effective is its actor per se. By multiplying the finding of TDM and BWM, the net coefficient degree of each actor can be calculating.

In the second stage, using this factor as the fraction of revenue-sharing, a new revenue-sharing coordination contract will be introduced. It's necessary that using the fuzzy DEMATEL method, each actor's share of the movie budget gets identified as revenue-sharing wage. Fig. 2 shows the whole methodology in a glimpse.

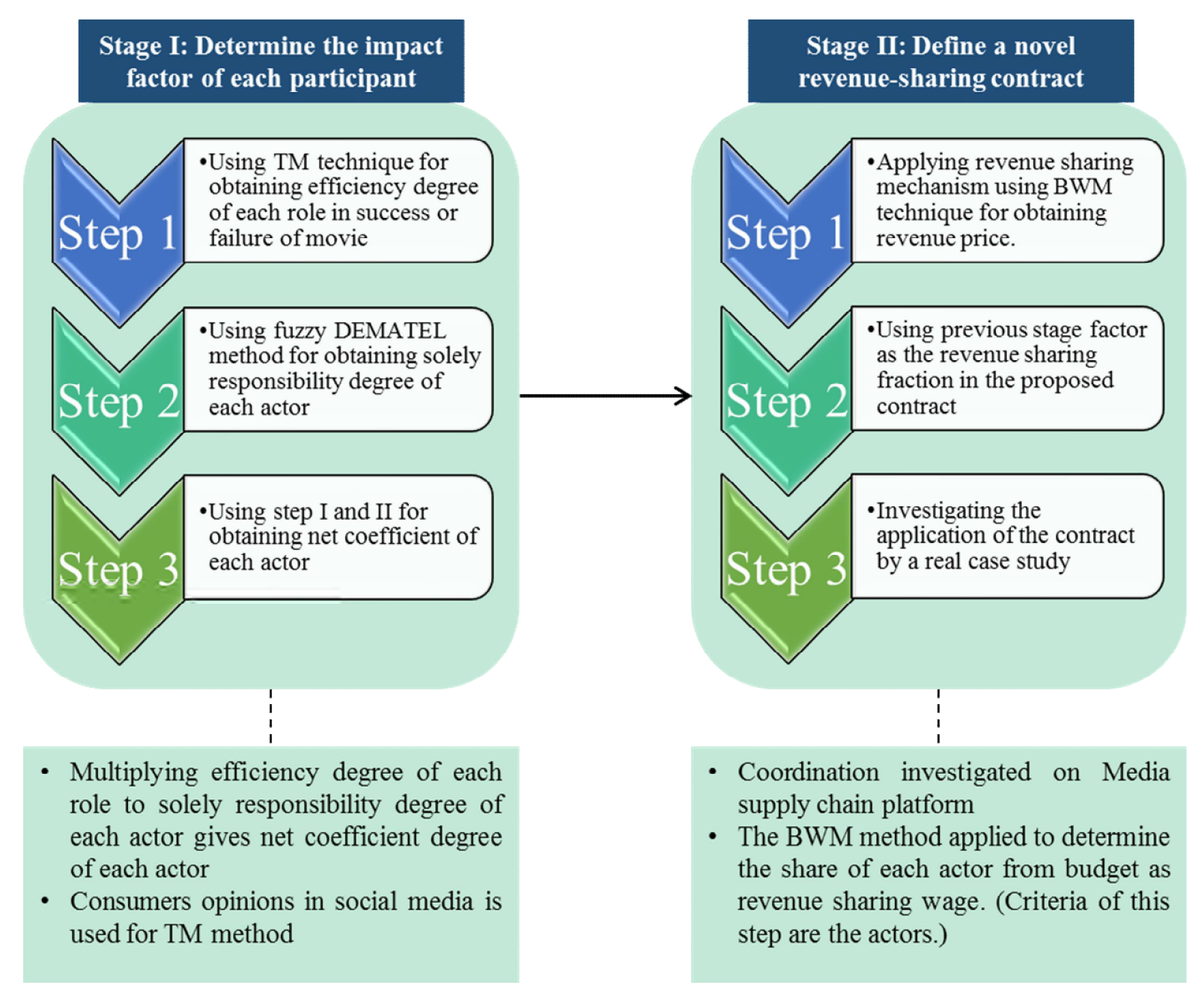

Fig. 2 Summary of the methodology

Used notations in this methodology are introduced in Table 2 as follows:

Table 2. Table of notations

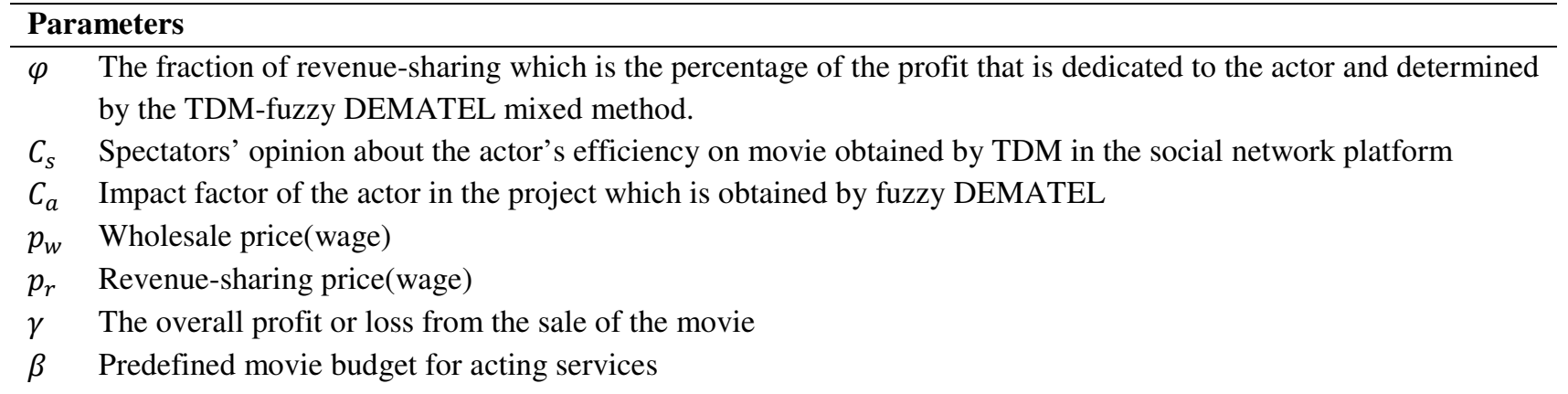


$\alpha_{i} \quad$ The factor that shows how much of the movie budget is paid to each actor as revenue-sharing price. $\alpha_{1}$ is the factor that is relevant to the discussed actor. (BWM weights)

$P_{B} \quad$ Project total budget

$P_{I} \quad$ Project total income

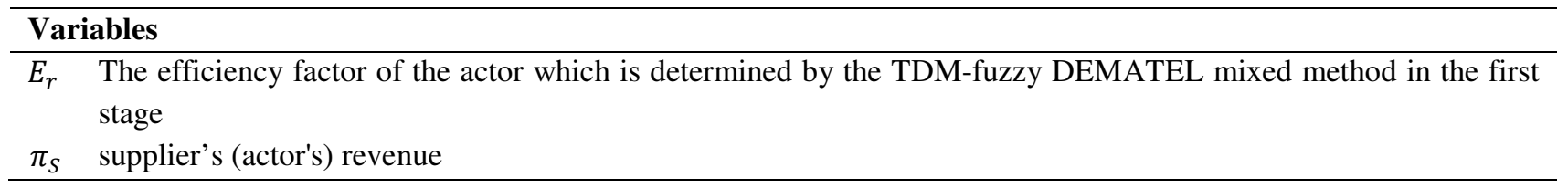

\subsection{Stage I: determining the revenue rate of each actor}

In step one, based on the TDM method, considering spectators' comments on the Instagram platform and investigating their sentiment, the efficiency degree of each actor in the success or failure of the movie is obtained.

Since most of the spectators cannot distinguish the other participants' work influence on actors' work, in step two, relying on the fuzzy DEMATEL method and benefiting the expert's opinion, we will determine how influential the actor himself was in his role. For example, how much of the success is due to the makeup artist's work and how much due to the actor's work.

In the last step of this stage, by integrating two previous steps results, the revenue rate of each actor can be achieved. This revenue rate is used in the proposed revenue-sharing contract to coordinate the media SC in a fair scientific way.

\subsubsection{Step I: determining the efficiency factor of each actor based on spectators' opinion}

According to recent researches proposed in the literature review section, the usage of data mining methods is growing day by day. TDM is a data mining approach for obtaining information by extracting meaningful numeric indices from the text. This method follows five steps to mine the information (Kumar \& Ravi, 2016).

1. Text preprocessing: It involves text cleanup (removing unnecessary information), tokenization, and part of speech.

2. Text transformation: also known as attribute generation. There are two ways for transforming text documents, the bag of words, and vector space.

3. Feature selection: also known as attribute selection or variable selection. In this step, a proper subset of bold features for model creation.

4. Data mining: using classic data mining methods is merged with the TDM in this step.

5. Evaluation: evaluating the results is one of the most important steps in the TDM technique.

6. Application: there are many areas that TDM may be applied, web mining, medical, resume filtering, etc.

One of the most efficient branches of TDM is sentiment analysis. Sentiment analysis(SA) is a tool that uses TDM for extracting and classification of opinions and emotions within the text. It could be used for understanding customers' feelings and opinions about the product and to hear the voice of the customer (VOC). 
SA uses various natural language processing (NLP) algorithms including (Alsaqer \& Sasi, 2017; Dreisbach, Koleck, Bourne, \& Bakken, 2019):

- Rule-based systems that are based on a set of rules which are manufactured manually.

- Automatic systems that benefiting machine learning techniques.

- Hybrid systems are a combination of both rule-based and automatic systems.

We believe that determining the wages of suppliers and manufacturers without considering consumers' opinions is neither fair nor scientific. Hence, it's necessary to investigate consumers' sentiments about the product. In this article, considering its scope of research (cinema industry), we used the TDM approach to analyze the spectators' sentiments and gain their opinion about actors. We want to understand how influential each actor has been on spectators' opinions about the success or failure of the project. Because of the Rule-based systems' high precision, this method is used for modeling this article.

\subsubsection{Step II: determining the impact factor of each actor in the project}

To the best of our knowledge, most of the spectators of a movie cannot discern the impact of other people's work on each other, and if they asserted that they think that one of the actors did a great job on the movie and made that film successful, they simply didn't consider the influence of makeup artists, screenwriters, etc. This is not just for cinema actors. In any SC, participants have an undeniable effect on each other work. So in this article, the fuzzy DEMATEL method is used to obtain the impact factor of each actor in the project. In more accurate words, in this step, we considered participants of a movie-making project as criteria of fuzzy DEMATEL technique to determine how much success or failure of a movie belongs to the actor himself.

Fuzzy DEMATEL proposed by Lin and Wu (2008) is one of the new methods of MCDM using the following steps:

1. Form a group of experts

2. Define the decision criteria and determining the linguistic scales. Table 3 has listed the linguistic scales used in this method and their corresponding values.

Table 3. The linguistic scales and their corresponding values

\begin{tabular}{|c|c|c|}
\hline The corresponding TFN & Linguistic term & Scale \\
\hline$(0,0,0.1)$ & Very low influence & 1 \\
\hline$(0,0.1,0.3)$ & Low in influence & 2 \\
\hline$(0.1,0.3,0.5)$ & Moderately low influence & 3 \\
\hline$(0.3,0.5,0.7)$ & No influence & 4 \\
\hline$(0.5,0.7,0.9)$ & Moderately high influence & 5 \\
\hline$(0.7,0.9,1)$ & High in influence & 6 \\
\hline$(0.9,1,1)$ & Very high influence & 7 \\
\hline
\end{tabular}

3. Create the Fuzzy Matrix Initial direct communication collecting expert opinions.

4. Normalize fuzzy matrix direct relation. To reaching this goal, linear scale conversion is used as a normalization formula to convert benchmark scales to tantamount criteria. 


$$
\begin{aligned}
& \tilde{a}_{i j}=\sum_{j=1}^{n} \tilde{Z}_{i j}=\left(\sum_{j=1}^{n} l_{i j} \cdot \sum_{j=1}^{n} m_{i j} \cdot \sum_{j=1}^{n} r_{i j}\right) \\
& r=\max _{1 \leq i \leq n}\left(\sum_{j=1}^{n} r_{i j}\right) \\
& \tilde{X}=\left[\begin{array}{ccc}
\tilde{X}_{11} & \cdots & \tilde{X}_{1 n} \\
\vdots & \ddots & \vdots \\
\tilde{X}_{m 1} & \cdots & \tilde{X}_{m n}
\end{array}\right] \\
& \tilde{X}_{i j}=\frac{\tilde{Z}_{i j}}{r}=\left(\frac{l_{i j}}{r} \cdot \frac{m_{i j}}{r} \cdot \frac{r_{i j}}{r}\right)
\end{aligned}
$$

5. Calculate the fuzzy matrix of the total relationship. First, the inverse of the normal matrix has to be calculated, then subtract from matrix I, and finally multiply the normal matrix in the resulting matrix.

$$
\begin{aligned}
& {\left[l_{i j}^{\prime \prime}\right]=X_{l} \times\left(I-X_{l}\right)^{-1}} \\
& {\left[m_{i j}^{\prime \prime}\right]=X_{m} \times\left(I-X_{m}\right)^{-1}} \\
& {\left[r_{i j}^{\prime \prime}\right]=X_{r} \times\left(I-X_{r}\right)^{-1}}
\end{aligned}
$$

6. Create and Analyze the casual Chart. For this purpose, first, the sum of the elements of each row $(D i)$ and the sum of the elements of each column $(R i)$ of the fuzzy matrix have to be calculated. The sum of the elements in each row $(D)$ for each factor indicates the extent to which that factor affects other system factors. The sum of the elements of the column $(R)$ for each factor indicates the degree of influence that factor has on other factors in the system. Then the values of $(D+R)$ and $(D-R)$ can be obtained easily. To draw a causal diagram, like the DEMTEL method, we have to defuzzify these two values the horizontal vector $(D+R)$ is the degree of influence of the desired factor in the system. In other words, the higher the $(D+R)$ factor, the more it interacts with other system factors. After defuzzifiying the numbers, a Cartesian coordinate system is drawn. In this device, the longitudinal axis represents the values

\begin{tabular}{|c|c|c|}
\hline Criteria & participant & Discerption \\
\hline$C_{1}$ & Actor himself & In every movie, actors play a decisive part in success or failure \\
\hline$C_{2}$ & Makeup artist & Each movie maker has to consider the impact of makeup \\
\hline$C_{3}$ & Screenwriter & The screenwriter in a movie-making project's $\mathrm{SC}$ is a key element \\
\hline
\end{tabular}
of $(D+R)$ and the $(D-R)$ is the transverse axis. If the value $(D-R)$ is positive, the factors are causal, whereas if the value $(D-R)$ is negative, the factors belong to the effect group Since fuzzy DEMATEL will not give us weights for criteria, based on the method presented by Tian et al. (2019), the criteria weights are found using fuzzy DEMATEL. Table 4 listed the defined criteria of this step.

Table 4. Discerption of each criterion in the first step 


$\begin{array}{ccc}C_{4} & \text { Visual effects producer } & \begin{array}{l}\text { Dress designing has a major influence on spectators' opinion about the } \\ \text { movie } \\ C_{5}\end{array} \\ \text { Other participants } & \text { Other participants influence the actor's job such as Sound mixing, }\end{array}$

$$
C_{a}=C_{1}
$$

\subsubsection{Step III: obtaining net coefficient of each actor}

Now that we obtained the spectators' opinion about the actor's efficiency and determined the impact factor of the actor in the project, it is time to gain the net efficiency factor of the actor. Equation [4] is found for this purpose.

$C_{1} \times C_{s}=E_{r}$

Equation [5] asserts that the absolute value of the net efficiency factor of the actor has to be considered as the fraction of revenue-sharing.

$$
\varphi=\left|E_{r}\right|
$$

\subsection{Stage II: defining a novel revenue-sharing contract}

The general purpose of the revenue-sharing contract is to minimize the impact of uncertainty on the SC and motivate the retailer to order and hold a higher level of inventory. Since it's not probable that market periodic demand is exactly the same as the retailer's order quantity, it is easy to conclude that either an excess or a shortage of inventory will take place. Under a revenue-sharing contract, the supplier will commit to delivering the order quantity requested by the retailer at a price lower than the usual wholesale price. In return, the retailer commit that pays a share of the overall sale of the goods at the end of the period to the supplier. (Cachon \& Lariviere, 2005)

As it has mentioned, this article focused on the cinema industry, so we consider the film actors as suppliers and the management team as the retailer. According to the definition of revenue-sharing contracts, in the proposed contract, the actor receives less than the usual wholesale price, and the project management team commits to sharing a percentage of the overall movie profit with the actor. Using fuzzy DEMATEL in step I (section 3.2.1), the revenue-sharing price will be determined.

In the second step, the mathematical formulation of the proposed coordination contract has been explained.

\subsubsection{Step I: Determining the revenue-sharing price using the BWM}

The best worst method (BWM) is one of the novel techniques in multi-criteria decision-making (MCDM), which has proposed by Rezaei $(2015,2016)$. The advantage of this method is that it requires fewer comparative data than similar methods, and its reliability is much higher. The steps of the BWM method are as follows:

1. Determine the set of decision criteria. Needless to say that the criteria of this step are different actors in the project. Because of the large number of the criteria that has not been mentioned.

2. Determine the best and the worst criteria (without comparison).

3. Determine the best criteria preference over all the others, using 1 to 9 numbers.

4. Determine the worst criteria preference over all the others, using 1 to 9 numbers. 
5. Compute the optimized weight of each criterion. Model [6] is the linear best-worst method. Benefiting this model, the optimized weight of criteria can be calculated.

$\min \varepsilon^{l}$

S.t

$\left|w_{B}-a_{B j} w_{j}\right| \leq \varepsilon^{l} \quad \forall j$

$\left|w_{j}-a_{j W} w_{W}\right| \leq \varepsilon^{l} \quad \forall j$

$\sum_{j} w_{j}=1$

$w_{j} \geq 0$

$\forall j$

In the above model $a_{B j} \cdot a_{j w} \cdot w_{B} \cdot w_{W} \cdot w_{j}$ shows the relative preference of the best criteria to criterion $j$, the relative preference of criterion $i$ to the worst criteria, the weight of best criteria and the weight of the worst criteria, and the weight of the criteria $j$, respectively.

1.5.2. Step II: Mathematical formulation of the proposed contract

$$
\pi_{S}\left(p_{r} . \varphi\right)= \begin{cases}p_{r}+\varphi \cdot \gamma & \text { If: } E_{r} \geq 0 \\ p_{r}-\varphi \cdot \gamma & \text { If: } E_{r}<0\end{cases}
$$

Equation [7] is the actor's determined wage. At first, before the filming, the actor will receive the revenue-sharing wage, and after the screening and determining the amount of profit or loss of the movie based on stage I steps fraction of revenue-sharing will be identified. If the actor was efficient in the success of the movie, according to the fraction of revenue-sharing, he gets his share of the film's profits. But if the actor was one of the failure factors of the movie, he has to compensate his share of the film's loss.

$$
p_{r}<p_{w}
$$

Equation [8] asserts that revenue-sharing wage is less than wholesale wage. Although this relation is self-evident, we are reasonably obliged to mention it.

As shown in equation [9], to obtain the revenue-sharing price of each actor, we used an MCDM method once more. This time, using the fuzzy DEMATEL technique, considering the interaction of actors, each actor's share of the film's budget is determined and paid as the revenue-sharing price to the actor.

$$
\begin{aligned}
& p_{r}=\beta \cdot \alpha_{1} \\
& \gamma=P_{I}-P_{B}
\end{aligned}
$$




\section{Case study}

For a closer look at the presented model's application, we used a case study. In this section, the information of this case study is provided. For avoiding any further conflict about the movie, here we do not mention the name of the movie, actors, or decision-makers.

The movie in question is one of the most controversial superhero movies in the last years. There were so many negative critics from famous experts and magazines. But, according to the fact that it grossed about 856.1 million $\$$, it is obvious that it made its way to its spectators' heart. With a 100116 million $\$$ budget, this movie became the sixth most profitable release of that year.

The lead role of this movie had a critical effect on the movie's profitability. Despite that many people believe the actor has saved the movie, there is no significant change in his revenue. As mentioned in the above paragraphs, the main idea of this article is to decrease the unfairness in the media SC and cinema industry. So we decided to investigate our new coordination contract on the lead actor performance and revenue. All the steps of the proposed methodology will be examined in this section.

\subsection{Determining the revenue fraction factor of the lead actor}

In this stage, after discovering and analyzing the viewers' opinion about the lead actor's attendance in the movie and normalizing the result by multiplying it into experts' opinions, we obtain a revenue fraction factor of the lead actor.

\subsubsection{Step I: Determining the efficiency factor of the lead actor based on spectators' reviews}

To obtain viewers' opinions about the lead actor's efficiency on the movie's profit, we mined for people comments on Twitter, Instagram posts (the movie's official account), and also reviews on famous web pages including IMDb, rotten tomatoes, and google audience reviews. Using rapid miner, sentiment analysis of the comments took place. Fig. 3 shows the process that has been exerted to analyze the sentiment polarity of the reviewers' comments.

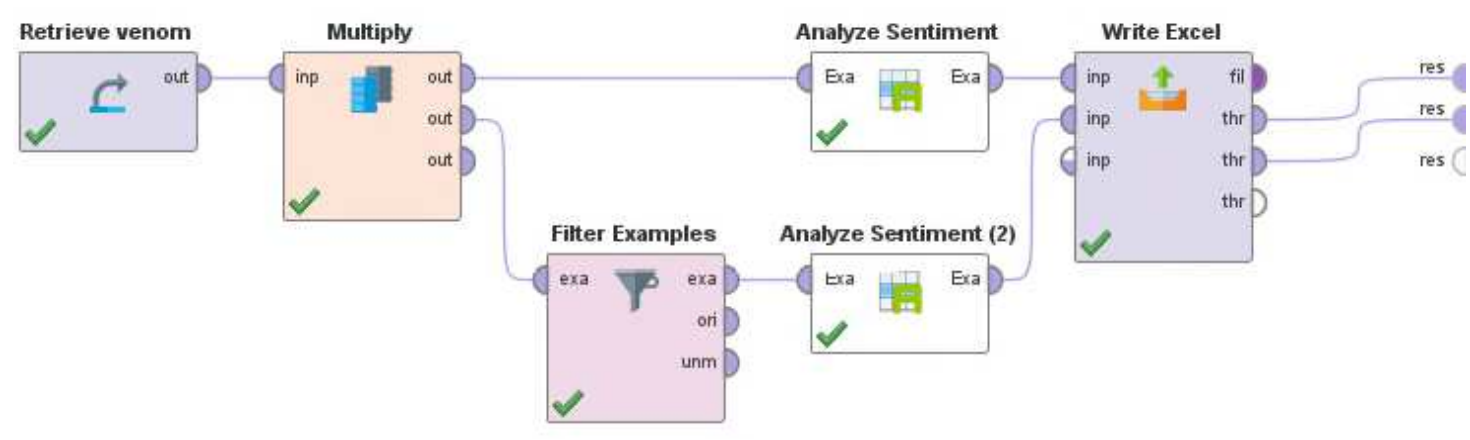

Fig. 3 Sentiment analysis process in rapid miner

Just as shown in figure 3, two excel sheets have been created. The first one contained the sentiment of spectators about the movie in general, benefitting analyze sentiment (1) operator, and the second one shows the result of analyzing sentiment (2) operator after filtering the comments and obtaining ones that were related to the lead actor's performance.

The Analyze sentiment operator gives the polarity and polarity confidence level (0-1). Each comment can be identified as positive, neutral, or negative. A number $(1,0,-1)$ has dedicated to each 
comment. 1 for positive, 0 for neutral, and -1 for negative. For calculating the efficiency factor, we multiplied this number to polarity confidence level number and the number of importance (which is the number of the likes that comment collected or the number of retweets).

The total efficiency factor of the film, in general, was calculated 278460, and the total efficiency factor of the lead actor's performance was calculated 33214.8. Dividing these two numbers, according to section 3.1.1. shows the efficiency factor of the lead actor in the movie's success.

Total efficiency factor of the lead actor's performance

Total efficiency factor of the film in general $=$ Efficiency factor of the lead actor in the movie success

$$
\Rightarrow \frac{33214.8}{278640}=0.11928
$$

1.6.2. Step II: Determining the impact factor of the lead actor in the project

To the best of our knowledge, most of the comments were sent by people who don't have any expertise in the cinema industry so as mentioned in section 3.1.2. Using the fuzzy DEMATEL method, we extracted experts' opinions about how much the lead actor's performance was influenced by other participants. In other words, how much of people's opinion was because of the lead actor's performance in his role. Table 5 asserts the weights calculated through the fuzzy DEMATEL method. These weights are named as the sole responsibility degree of different participants.

Table 5. Obtained weights for each criterion(participant) using fuzzy DEMATEL

\begin{tabular}{|c|c|c|}
\hline Criteria & Participant & Weight \\
\hline$C_{1}$ & Actor himself & 0.24150 \\
\hline$C_{2}$ & Makeup artist & 0.13688 \\
\hline$C_{3}$ & Screenwriter & 0.21248 \\
\hline$C_{4}$ & Visual effects producer & 0.23006 \\
\hline$C_{5}$ & Other participants & 0.17909 \\
\hline
\end{tabular}

\subsubsection{Step III: Obtaining net coefficient of the lead actor}

The revenue fraction factor of the lead actor has been defined using the TDM-BWM technique, as follows. The efficiency factor of the lead actor in the movie success multiplies to the lead actor's solely responsibility degree is equal to the lead actor's net coefficient degree.

$$
E_{r}=C_{1} \times C_{s} \Rightarrow 0.11928 \times 0.24150=0.0288
$$

It illuminates that our case study actor is responsible for more than 5 percent of the movie's profit. This factor is used in the proposed revenue-sharing coordination contract as the revenue fraction factor.

$$
\varphi=\left|E_{r}\right|=0.0288
$$

\subsection{Defining a novel revenue-sharing contract}

Now that we calculated the revenue fraction factor, it's time to define our novel coordination contract. But first, we have to determine the revenue-sharing price calculated by experts' opinions and the BWM technique. Then the mathematical formulation of the proposed contract has to be investigated. 
1.7.1. Step I: Determining the revenue-sharing price using BWM

In this step, we have to assume that the producer dedicates 10 million $\$$ to contract with the mentioned actors in Table 6. Using the BWM technique, each actor's share of the budget is determined, as showed in Table 6.

Table 6. Obtained weights for each criterion(actor) using BWM

\begin{tabular}{ccccc}
\hline Criteria & & Actors & & Weight \\
\cline { 1 - 1 }$\alpha_{1}$ & & The lead actor & & 0.57707055214724 \\
$\alpha_{2}$ & & The lead actress & & 0.12078220858895 \\
$\alpha_{3}$ & & Supporting actor 1 & & 0.14493865030674 \\
$\alpha_{4}$ & & Supporting actor 2 & & 0.10352760736196 \\
$\alpha_{5}$ & & Supporting actor 3 & & 0.05368098159509 \\
\hline
\end{tabular}

According to equation [9], the lead actor's contract's revenue-sharing price is calculated.

$$
p_{r}=\beta . \alpha_{1}=10000000 \times 0.5770=5770000 \$
$$

1.7.2. Step II: Mathematical formulation of the proposed contract

As mentioned before, the movie's budget was 116 million $\$$, and the box office was 856.1 million $\$$ therefore, it's needless to say that the movie was profitable. So for defining the revenue-sharing coordination contract equation [7] are used as follow:

$$
\begin{gathered}
\pi_{S}\left(p_{r} . \varphi\right)=p_{r}+\varphi \cdot \gamma \\
\pi_{S}\left(p_{r} . \varphi\right)=5770000+0.0288 \times 740100000=27084880 \$
\end{gathered}
$$

\section{Sensitivity analysis and discussion}

To demonstrate the efficiency and sensitivity of the proposed model, in this section, we examine some numerical experiments which can be considered as new case studies. The parameters for three

\begin{tabular}{|c|c|c|c|c|}
\hline Parameter & Case study & $1^{\text {st }}$ example & $2^{\text {nd }}$ example & $3^{\text {rd }}$ example \\
\hline$\varphi$ & 0.0288 & 0.0284 & 0.0243 & 0.0175 \\
\hline$C_{s}$ & 0.24150 & -0.12156 & -0.24650 & 0.15489 \\
\hline$C_{a}$ & 0.11928 & 0.23418 & 0.09867 & 0.11356 \\
\hline$p_{w}$ & $7000000 \$$ & $11000000 \$$ & $10500000 \$$ & $6500000 \$$ \\
\hline$p_{r}$ & $5770000 \$$ & $9740500 \$$ & $10317600 \$$ & $5880600 \$$ \\
\hline$\gamma$ & $740100000 \$$ & $-16000000 \$$ & $370000000 \$$ & $-400000 \$$ \\
\hline$\beta$ & $10000000 \$$ & $23000000 \$$ & $18000000 \$$ & $9000000 \$$ \\
\hline$\alpha_{i}$ & 0.5770 & 0.4235 & 0.5732 & 0.6534 \\
\hline$P_{B}$ & $116000000 \$$ & $140000000 \$$ & $90000000 \$$ & $103000000 \$$ \\
\hline$P_{I}$ & $856100000 \$$ & $124000000 \$$ & $480000000 \$$ & $102600000 \$$ \\
\hline$E_{r}$ & 0.0288 & -0.0284 & -0.0243 & 0.0175 \\
\hline$\pi_{S}$ & $27084880 \$$ & $5196500 \$$ & $\leq 10317600 \$$ & $\geq 5880600 \$$ \\
\hline
\end{tabular}
numerical examples are listed in Table 7.

Table 7. Parameter values of numerical examples 
Needless to say that based on the movie's profitability and actor's efficiency, four different scenarios may occur. Table 8 propose a comprehensive discussion about these four scenarios and their relevant examples mentioned in Table 7.

Table 8. Probable scenarios and relevant examples

\begin{tabular}{|c|c|c|c|}
\hline $\begin{array}{c}\text { Movie's } \\
\text { profitability }\end{array}$ & $\begin{array}{c}\text { Actor's } \\
\text { efficiency }\end{array}$ & $\begin{array}{l}\text { Relevant } \\
\text { example }\end{array}$ & Discussion \\
\hline Profitable & Efficient & Case study & $\begin{array}{l}\text { According to spectators' and experts' opinions, the lead } \\
\text { actor's performance is positive, and the movie is profitable. } \\
\text { Just as examined in section } 4 \text {, the actor earns } 20084880 \$ \\
\text { more than the wholesale price which he used to receive. }\end{array}$ \\
\hline Loss-making & Detrimental & $1^{\text {st }}$ example & $\begin{array}{l}\text { The movie is not profitable. Based on the proposed TDM- } \\
\text { MCDM method, the actor is one of the reasons. So, according } \\
\text { to the methodology, he/she gets less than } 5803500 \$ \\
\text { wholesale price and compensates } 4544000 \$ \text { of the loss he/she } \\
\text { caused. }\end{array}$ \\
\hline Profitable & Detrimental & $2^{\text {nd }}$ example & $\begin{array}{l}\text { In this situation, we can't calculate the actor's accurate wage } \\
\text { based on the proposed methodology; But as mentioned in } \\
\text { Table } 7 \text {, revenue-sharing price is computed as the upper } \\
\text { bound of the third scenario }\end{array}$ \\
\hline Loss-making & Efficient & $3^{\text {rd }}$ example & $\begin{array}{l}\text { In this situation, we can't calculate the actor's accurate wage } \\
\text { based on the proposed methodology; But as mentioned in } \\
\text { Table } 7 \text {, the revenue-sharing price is computed as the lower } \\
\text { bound of the fourth scenario. }\end{array}$ \\
\hline
\end{tabular}

Based on the proposed case study, the following diagrams are presented to identify the sensitivity of the model to various parameters. A various possible situation that may occur for the movie has been depicted and examined in the following figures of this section.

Based on the changes in the project's income $\left(P_{I}\right)$ and project budget $\left(P_{B}\right)$, the actor's revenue $\left(\pi_{S}\right)$ has been portrayed in Fig. 4. For utter investigation in each layer different predefined movie budget for acting services $(\beta)$ has been involved. In other words, each surface represents the dependency of the actor's wage to project income and project budget on a specific predetermined budget for acting services. It's obvious that although changes in project income can make significant changes in the actor's wage, the project budget does not have much influence. Crystal clear the reason for this case is that the actor's budget is predetermined. If $\beta$ was directly dependent on the project budget (which it is in the real world but for easier calculating we presumed it predetermined), then $\pi_{S}$ was so sensitive against $P_{B}$ just like the way it is sensitive to the $\beta$ now. 


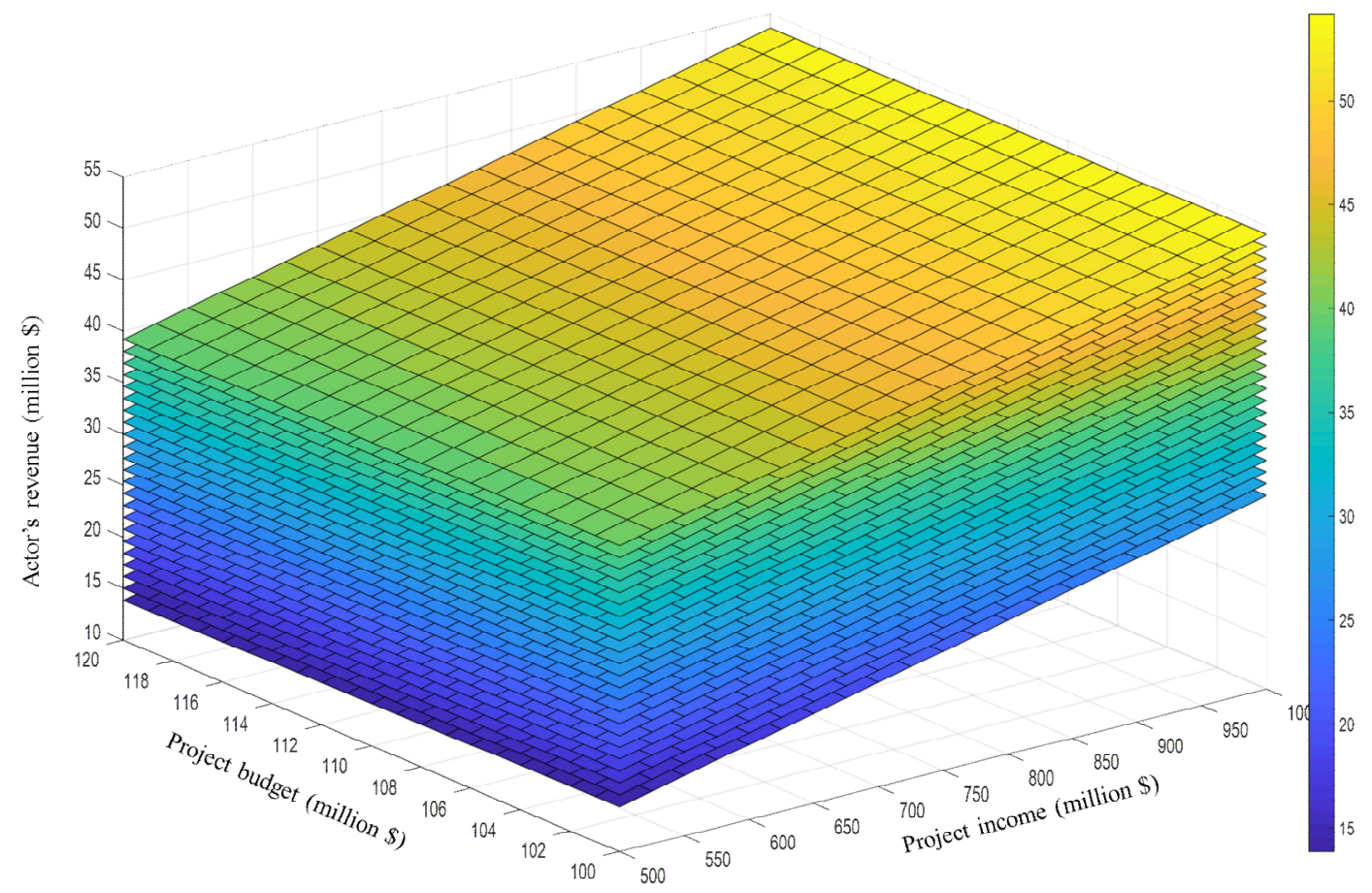

Fig. 4 Changes in actor's wages compared to changes in the project's budget, project's income, and Predefined movie budget for acting services in a profitable movie

Fig. 5-7 are dedicated to the actor's dependency level to each parameter. In the legend box of each figure, you can find another parameter that is concerned. The star asserts our case study situation so you can find better information about the movie.

Fig. 5 depicts the actor's revenue dependency on the project budget for acting services. This figure asserts that the higher level of the movie's acting services budget, the higher will be the actor's wage. Also, you can see this on the different levels of the movie's income.

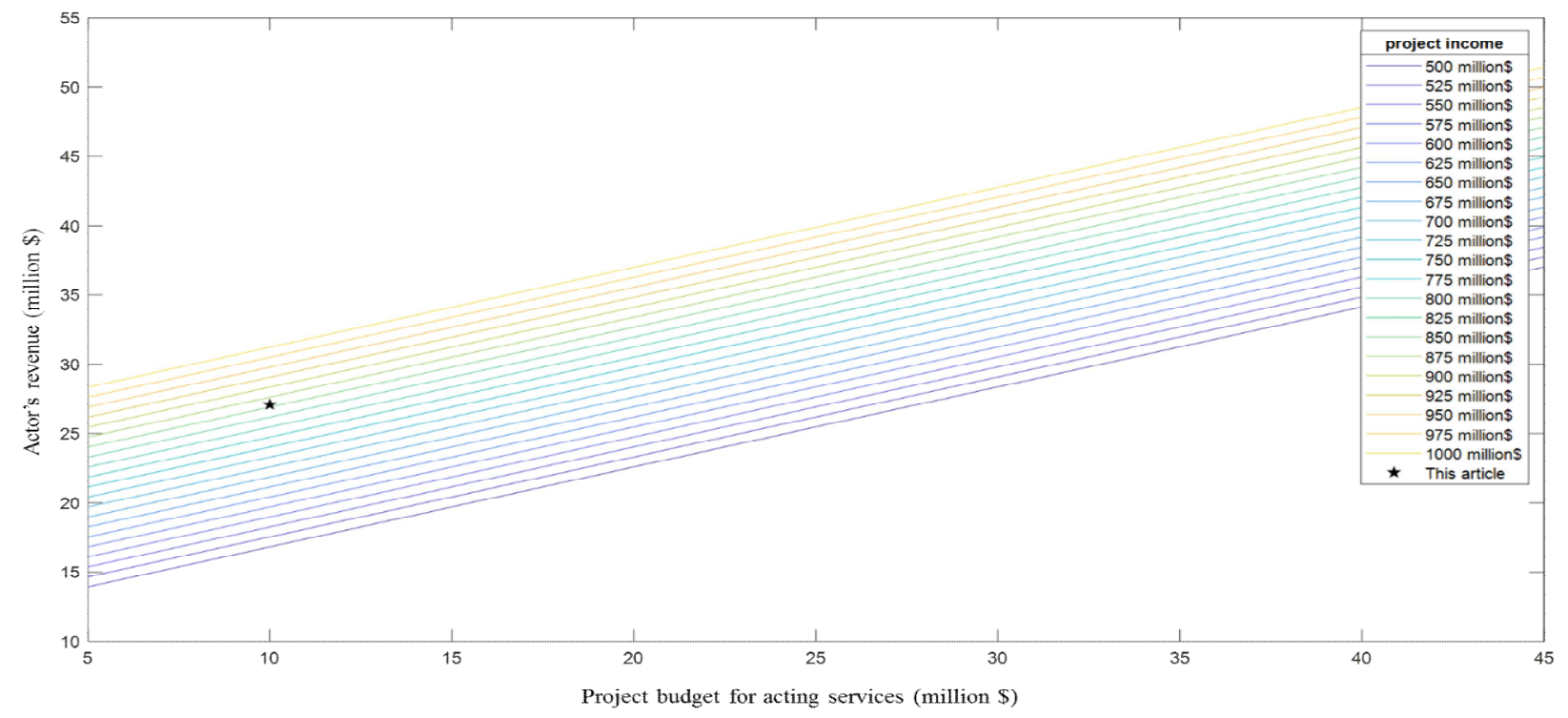

Fig. 5 Actor's revenue dependency on project budget for acting services

In Fig. 6, you can observe the actor's revenue dependency on project income. Besides, there is a direct relationship between the movie's income and the actor's wage. 


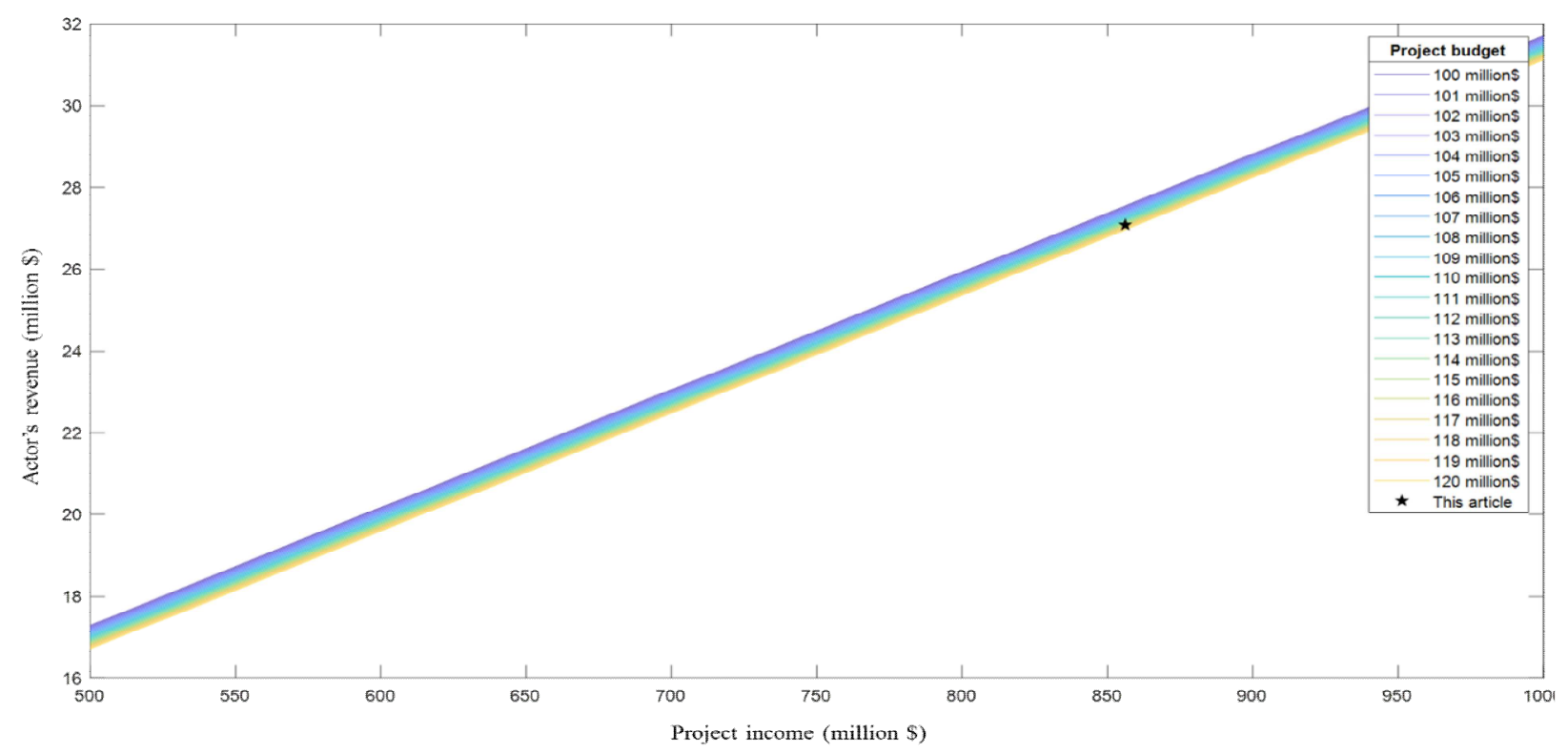

Fig. 6 Actor's revenue dependency on project income

Fig. 7 investigates the actor's revenue dependency on the project budget. As you can observe, this figure shows that a higher level of project budget makes a lower level of the actor's revenue. This is because we presumed that the movie's budget is not related to the acting services' budget, which is not like that in the real world.

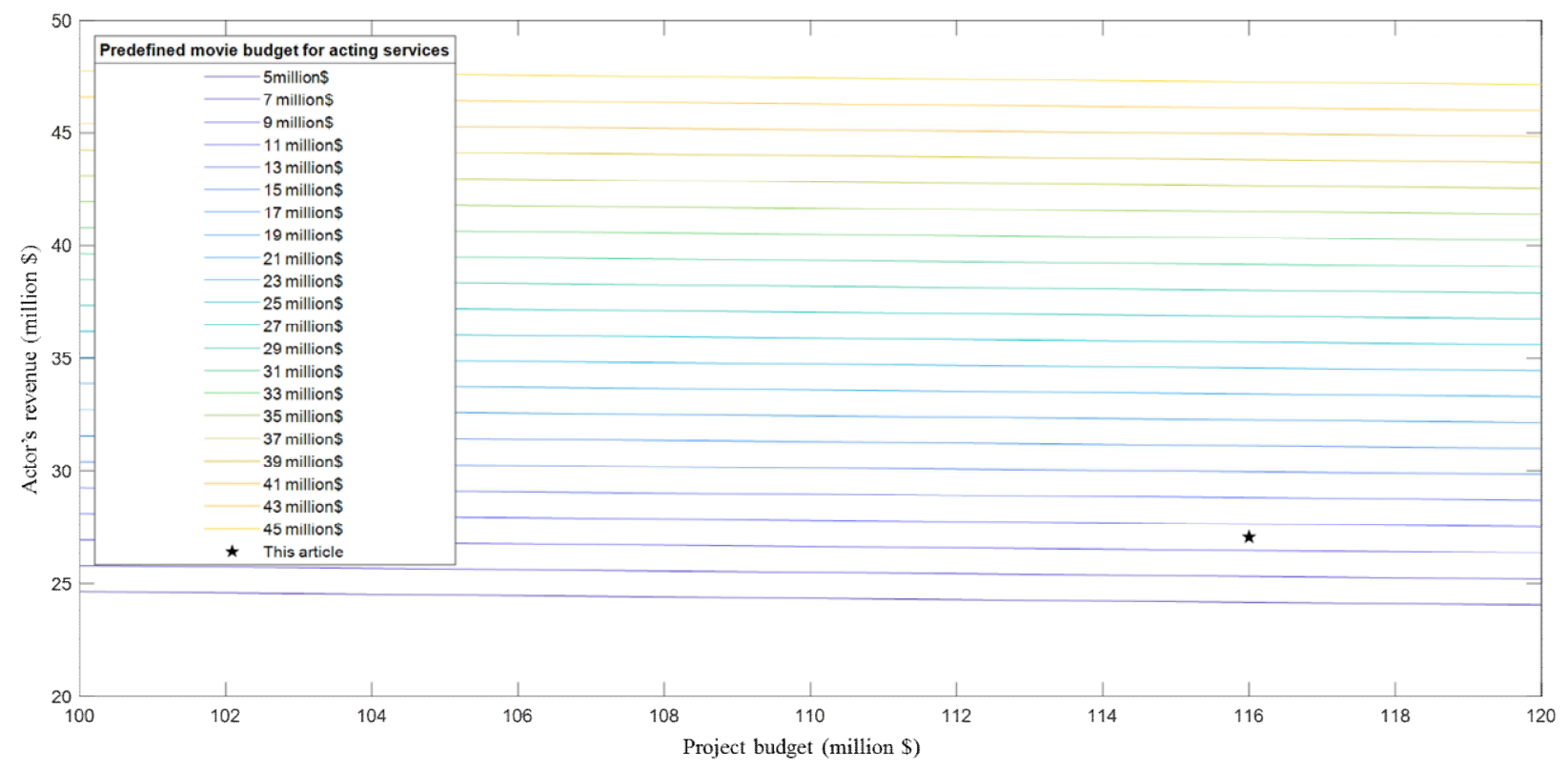

Fig. 7 Actor's revenue dependency on project budget

\section{Conclusion}

To the best of our knowledge, the most eligible way for fair WD is to take a step into SCs coordination. Throughout human history, many tools have been introduced, hoping to coordinate SCs. One of the most efficient tools in this matter is the coordination contract. Each coordination contract has drawbacks that need to be considered and updated. In this research, a novel revenue-sharing coordination contract has been defined, which uses the TDM method to extract the efficiency degree 
of each role in the success or the failure of the movie to make WD fairer. Meanwhile, the fuzzy DEMATEL technique has been applied to calculate the sole responsivity degree of each actor in their role. By multiplying these factors, we easily got the net coefficient factor we used as the revenuesharing fraction. By applying the BWM technique, revenue price got calculated. The movie is considered as the case study and investigated step by step in this very paper. At the end of this study, some brief sensitivity analysis has been proposed that could give valuable managerial insights.

The fair WD has been done according to novel methods of decision-making and based on the efficiency of actors. Considering people's opinions along with the expert's opinions made it reliable. The findings of this study confirm the professional reviews of the great critics of the cinema industry. This paper can help media supply chain decision-makers in many aspects. Here we reckon some of its benefits:

- Applying this method leads to a fair WD.

- Using this method, the actor does his best to accelerate the movie's income, which is his.

- This method prevents the movie from heavy loss, and in case of loss, it will share it with people in guilt.

We highly recommend that future researches use bargaining methods or game theory approach to calculate the actor's wage or use a data analytics approach to determine how much profit or loss the question actor has made.

\section{Compliance with Ethical Standards}

The authors declare that they have no conflict of interest. In addition, this article does not contain any studies with human participants or animals performed by the author. The undersigned authors declare that this manuscript is original, has not been published before and is not currently being considered for publication elsewhere.

Funding: Not applicable

Conflicts of interest/Competing interests: Not applicable

Availability of data and material: Not applicable

Informed consent: Not applicable

\section{Author contributions}

All authors contributed to the study conception and design. Material preparation, data collection and analysis were performed by Mohammad Alipour-Vaezi, Amir Aghsami and Masoud Rabbani. The first draft of the manuscript was written by Mohammad Alipour-Vaezi and all authors commented on previous versions of the manuscript. All authors read and approved the final manuscript.

\section{References}

Aghajani, M., Torabi, S. A., \& Heydari, J. (2020). A novel option contract integrated with supplier selection and inventory prepositioning for humanitarian relief supply chains. Socio-Economic Planning Sciences, 100780 . 
Alsaqer, A. F., \& Sasi, S. (2017). Movie review summarization and sentiment analysis using rapidminer. Paper presented at the 2017 International Conference on Networks \& Advances in Computational Technologies (NetACT).

Amrit, C., Paauw, T., Aly, R., \& Lavric, M. (2017). Identifying child abuse through text mining and machine learning. Expert Systems with Applications, 88, 402-418.

Arani, H. V., Rabbani, M., \& Rafiei, H. (2016). A revenue-sharing option contract toward coordination of supply chains. International Journal of Production Economics, 178, 42-56.

Araque, O., Corcuera-Platas, I., Sánchez-Rada, J. F., \& Iglesias, C. A. (2017). Enhancing deep learning sentiment analysis with ensemble techniques in social applications. Expert Systems with Applications, 77, 236-246.

Cachon, G. P., \& Lariviere, M. A. (2005). Supply chain coordination with revenue-sharing contracts: strengths and limitations. Management Science, 51(1), 30-44.

Canbulut, G., Köse, E., \& Arik, O. A. (2021). Handling of revenue sharing contracts within the scope of game theory. Soft Computing, 25(1), 321-329.

Chen, L.-C., Lee, C.-M., \& Chen, M.-Y. (2019). Exploration of social media for sentiment analysis using deep learning. Soft Computing, 1-11.

Dreisbach, C., Koleck, T. A., Bourne, P. E., \& Bakken, S. (2019). A systematic review of natural language processing and text mining of symptoms from electronic patient-authored text data. International journal of medical informatics.

Fu, C., Liu, W., \& Chang, W. (2018). Data-driven multiple criteria decision making for diagnosis of thyroid cancer. Annals of Operations Research, 1-30.

Greco, F., \& Polli, A. (2019). Emotional Text Mining: Customer profiling in brand management. International Journal of Information Management, 101934.

Hsueh, C.-F. (2014). Improving corporate social responsibility in a supply chain through a new revenue sharing contract. International Journal of Production Economics, 151, 214-222.

Hu, B., \& Feng, Y. (2017). Optimization and coordination of supply chain with revenue sharing contracts and service requirement under supply and demand uncertainty. International Journal of Production Economics, 183, 185-193.

Ismail, H. M., Belkhouche, B., \& Zaki, N. (2018). Semantic Twitter sentiment analysis based on a fuzzy thesaurus. Soft Computing, 22(18), 6011-6024.

Kumar, B. S., \& Ravi, V. (2016). A survey of the applications of text mining in financial domain. KnowledgeBased Systems, 114, 128-147.

Lariviere, M. A. (1999). Supply chain contracting and coordination with stochastic demand Quantitative models for supply chain management (pp. 233-268): Springer.

Li, J., Fong, S., Zhuang, Y., \& Khoury, R. (2016). Hierarchical classification in text mining for sentiment analysis of online news. Soft Computing, 20(9), 3411-3420.

Li, T., Zhang, R., Zhao, S., \& Liu, B. (2019). Low carbon strategy analysis under revenue-sharing and costsharing contracts. Journal of Cleaner Production, 212, 1462-1477.

Liang, L., Xie, J., Liu, L., \& Xia, Y. (2017). Revenue sharing contract coordination of wind turbine order policy and aftermarket service based on joint effort. Industrial Management \& Data Systems.

Lin, C.-J., \& Wu, W.-W. (2008). A causal analytical method for group decision-making under fuzzy environment. Expert Systems with Applications, 34(1), 205-213.

Lingcheng, K., Zhenning, Z., Jiaping, X., Jing, L., \& Yuping, C. (2019). Multilateral agreement contract optimization of renewable energy power grid-connecting under uncertain supply and market demand. Computers \& Industrial Engineering, 135, 689-701.

Liu, F., Wang, J., Liu, J., \& Kong, Y. (2019). Coordination of port service chain with an integrated contract. Soft Computing, 1-14. 
Ma, N., Gao, R., Wang, X., \& Li, P. (2020). Green supply chain analysis under cost sharing contract with uncertain information based on confidence level. Soft Computing, 24(4), 2617-2635.

Monkman, G. G., Kaiser, M. J., \& Hyder, K. (2018). Text and data mining of social media to map wildlife recreation activity. Biological conservation, 228, 89-99.

Nisa, R., \& Qamar, U. (2015). A text mining based approach for web service classification. Information Systems and e-Business Management, 13(4), 751-768.

Panja, S., \& Mondal, S. K. (2020). Exploring a two-layer green supply chain game theoretic model with credit linked demand and mark-up under revenue sharing contract. Journal of Cleaner Production, 250, 119491.

Pejic-Bach, M., Bertoncel, T., Meško, M., \& Krstić, Ž. (2020). Text mining of industry 4.0 job advertisements. International Journal of Information Management, 50, 416-431.

Raza, S. A. (2018). Supply chain coordination under a revenue-sharing contract with corporate social responsibility and partial demand information. International Journal of Production Economics, 205, 114.

Rezaei, J. (2015). Best-worst multi-criteria decision-making method. Omega, 53, 49-57.

Rezaei, J. (2016). Best-worst multi-criteria decision-making method: Some properties and a linear model. Omega, 64, 126-130.

Serna, A., \& Gasparovic, S. (2018). Transport analysis approach based on big data and text mining analysis from social media. Transportation research procedia, 33, 291-298.

Tan, X., Cai, Y., Xu, J., Leung, H.-F., Chen, W., \& Li, Q. (2020). Improving aspect-based sentiment analysis via aligning aspect embedding. Neurocomputing, 383, 336-347.

Tian, G., Liu, X., Zhang, M., Yang, Y., Zhang, H., Lin, Y., . . Li, Z. (2019). Selection of take-back pattern of vehicle reverse logistics in China via Grey-DEMATEL and Fuzzy-VIKOR combined method. Journal of Cleaner Production, 220, 1088-1100.

Tsao, Y.-C., \& Lee, P.-L. (2020). Employing revenue sharing strategies when confronted with uncertain and promotion-sensitive demand. Computers \& Industrial Engineering, 139, 106200.

Tsay, A. A., Nahmias, S., \& Agrawal, N. (1999). Modeling supply chain contracts: A review Quantitative models for supply chain management (pp. 299-336): Springer.

Wang, G., Ding, P., Chen, H., \& Mu, J. (2020). Green fresh product cost sharing contracts considering freshnesskeeping effort. Soft Computing, 24(4), 2671-2691.

Wei, Q., Li, S., Gou, X., \& Huo, B. (2019). Joint optimal decision of the shared distribution system through revenue-sharing and cooperative investment contracts. Industrial Management \& Data Systems.

Xia, W., Jiang, C., Wang, K., \& Zhang, A. (2019). Air-rail revenue sharing in a multi-airport system: Effects on traffic and social welfare. Transportation research part B: methodological, 121, 304-319.

Yan, B., Wu, X.-h., Ye, B., \& Zhang, Y.-w. (2017). Three-level supply chain coordination of fresh agricultural products in the Internet of Things. Industrial Management \& Data Systems.

Ye, W.-J., \& Lee, A. J. (2020). Mining sentiment tendencies and summaries from consumer reviews. Information Systems and e-Business Management, 1-29.

Yu, M., \& Guo, C. (2018). Using news to predict Chinese medicinal material price index movements. Industrial Management \& Data Systems.

Zhao, D., Chen, M., \& Gong, Y. (2019). Strategic information sharing under revenue-sharing contract: Explicit vs. tacit collusion in retailers. Computers \& Industrial Engineering, 131, 99-114. 
Figures

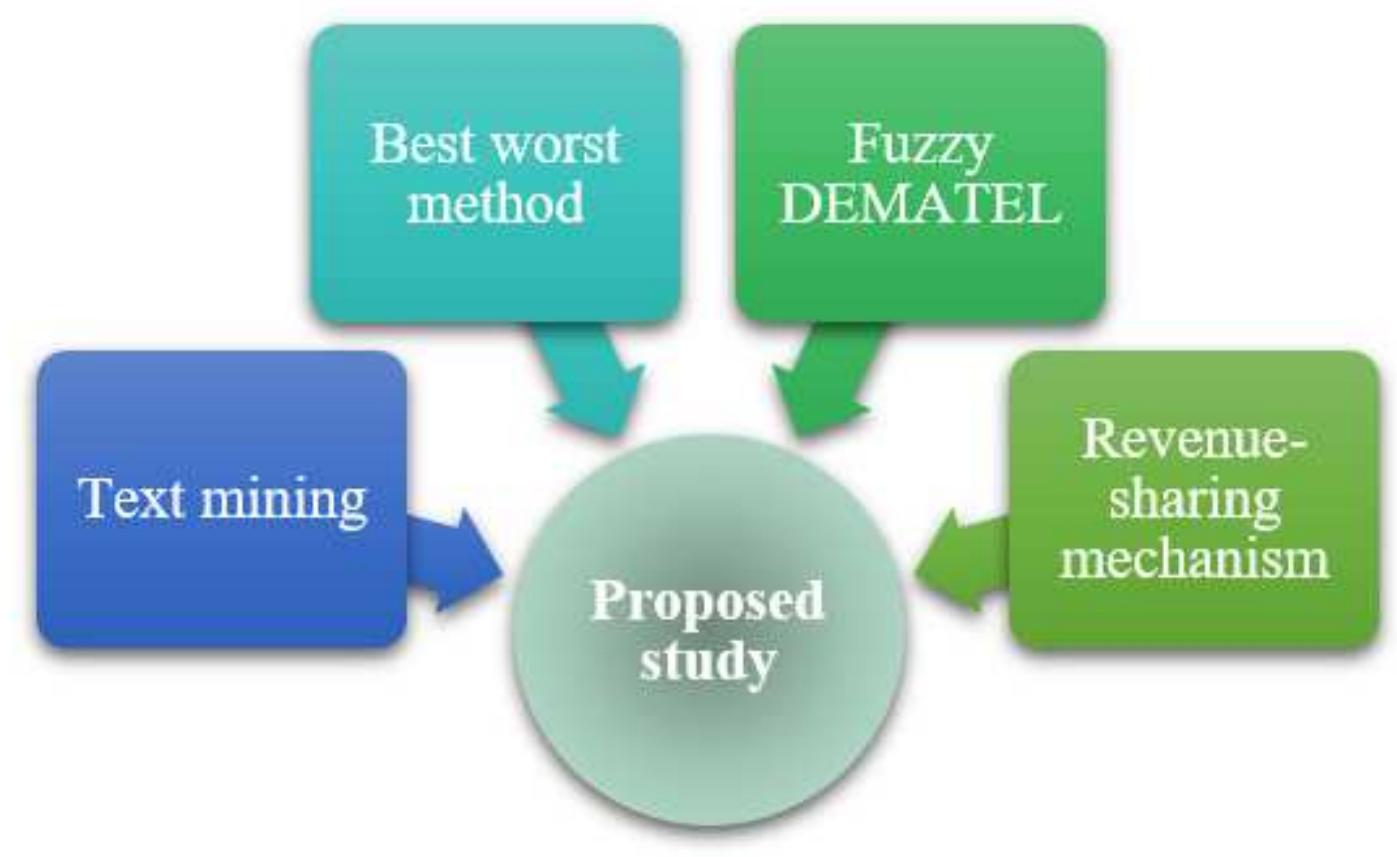

Figure 1

Summary of the article 
Stage I: Determine the impact

factor of each participant
Stage II: Define a novel

revenue-sharing contract

-Using TM technique for obtaining efficiency degree of each role in success or failure of movie

-Using fuzzy DEMATEL method for obtaining solely responsibility degree of each actor

\begin{tabular}{|l|l|} 
Step 2 & $\begin{array}{l}\text { responsibility degree of } \\
\text { each actor }\end{array}$ \\
\hline
\end{tabular}

-Using step I and II for obtaining net coefficient of Step 3 each actor

\section{Figure 2}

- Multiplying efficiency degree of each role to solely responsibility degree of each actor gives net coefficient degree of each actor

- Consumers opinions in social media is used for TM method

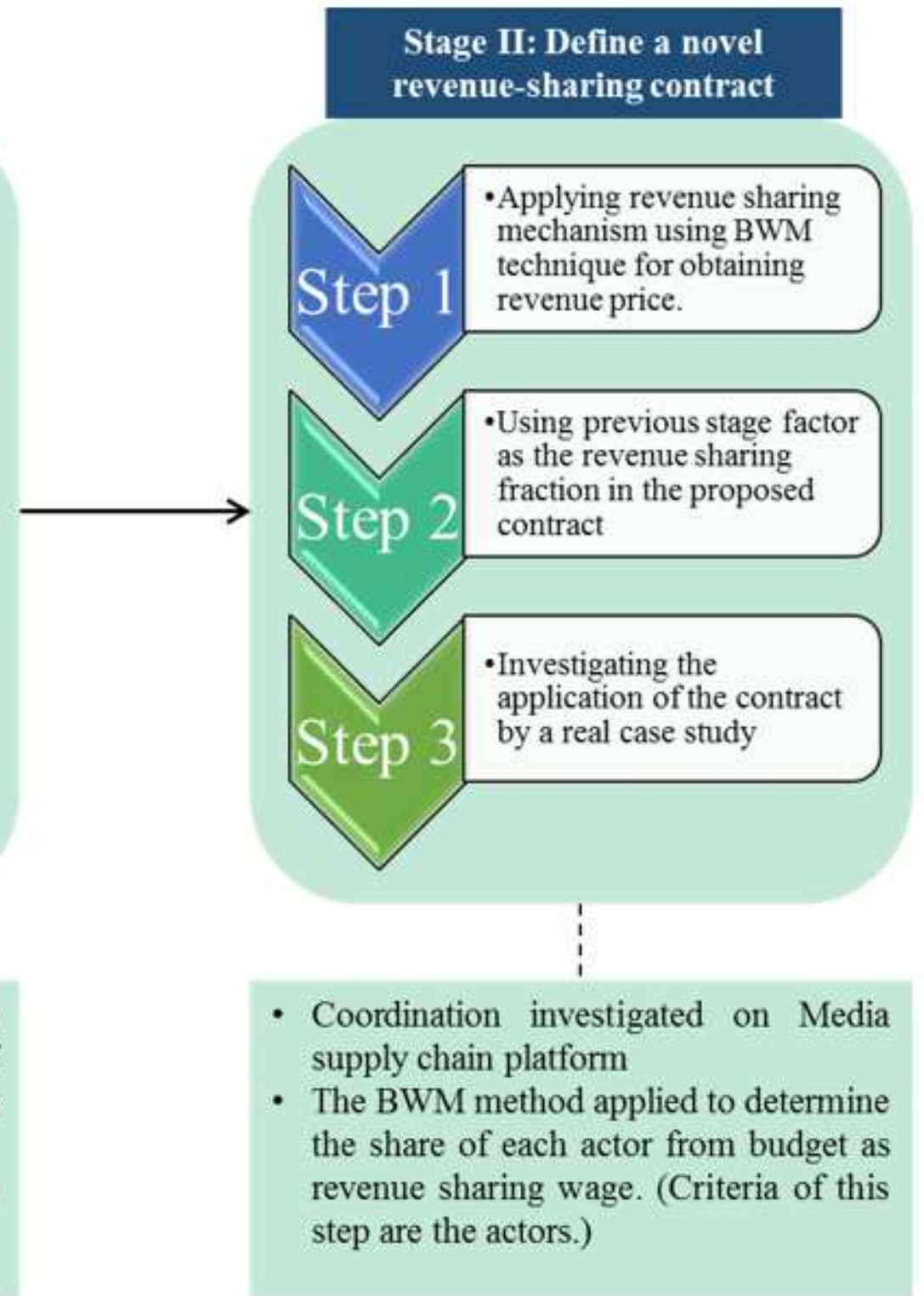

Summary of the methodology

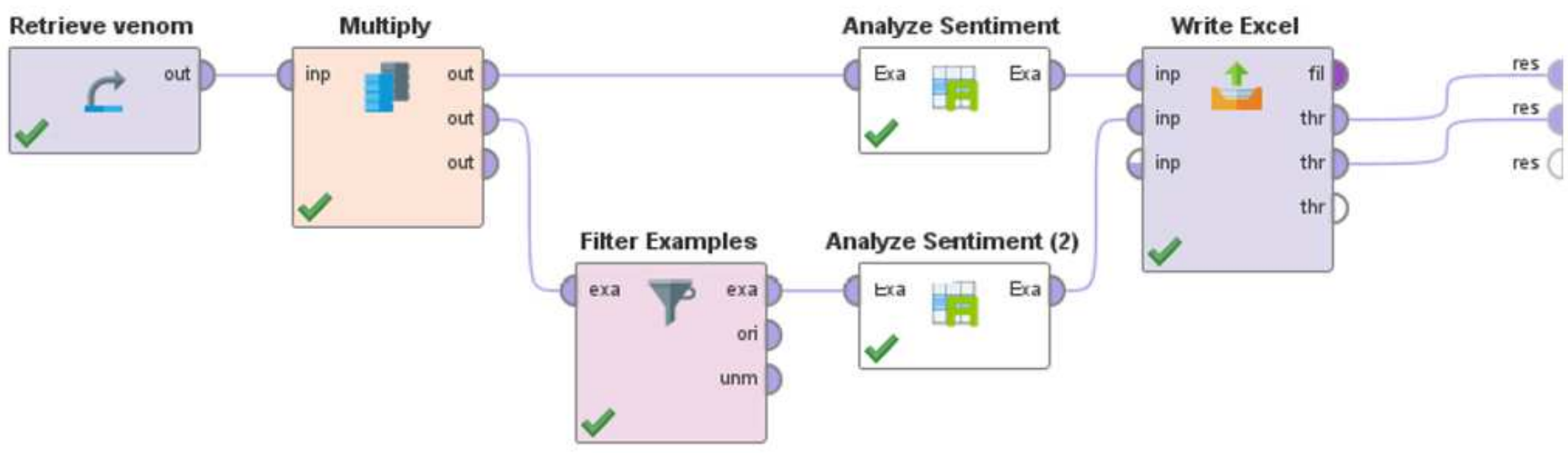


Sentiment analysis process in rapid miner

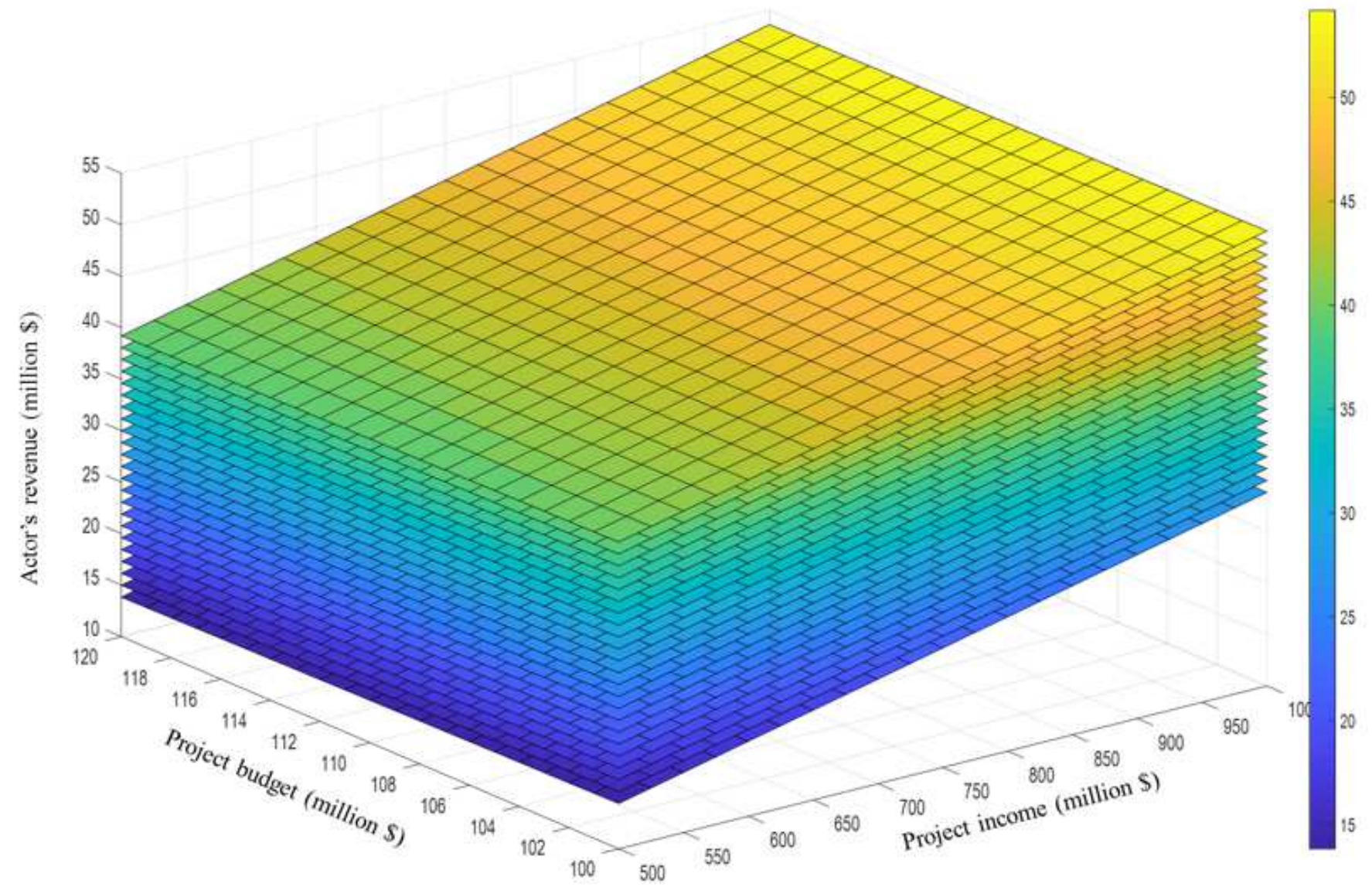

\section{Figure 4}

Changes in actor's wages compared to changes in the project's budget, project's income, and Predefined movie budget for acting services in a profitable movie

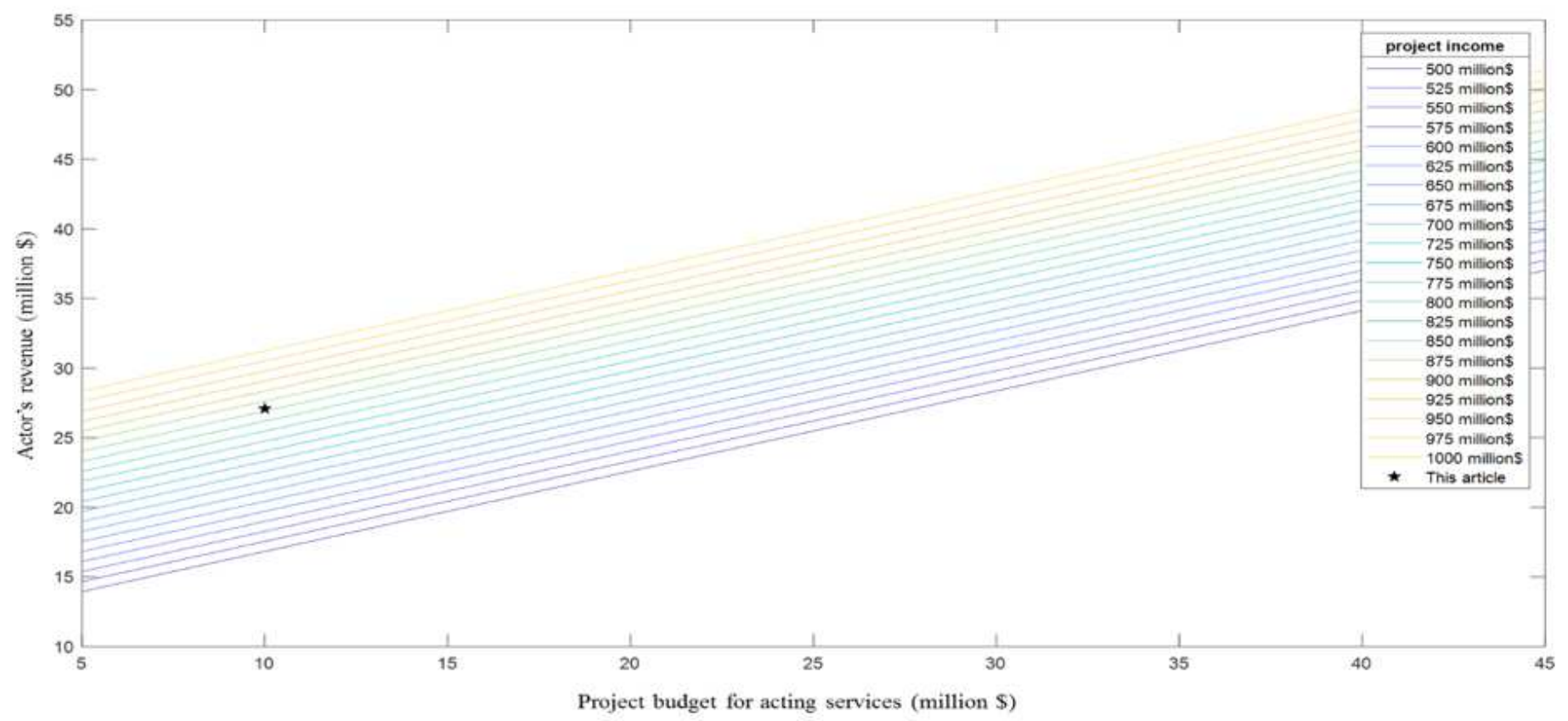


Figure 5

Actor's revenue dependency on project budget for acting services

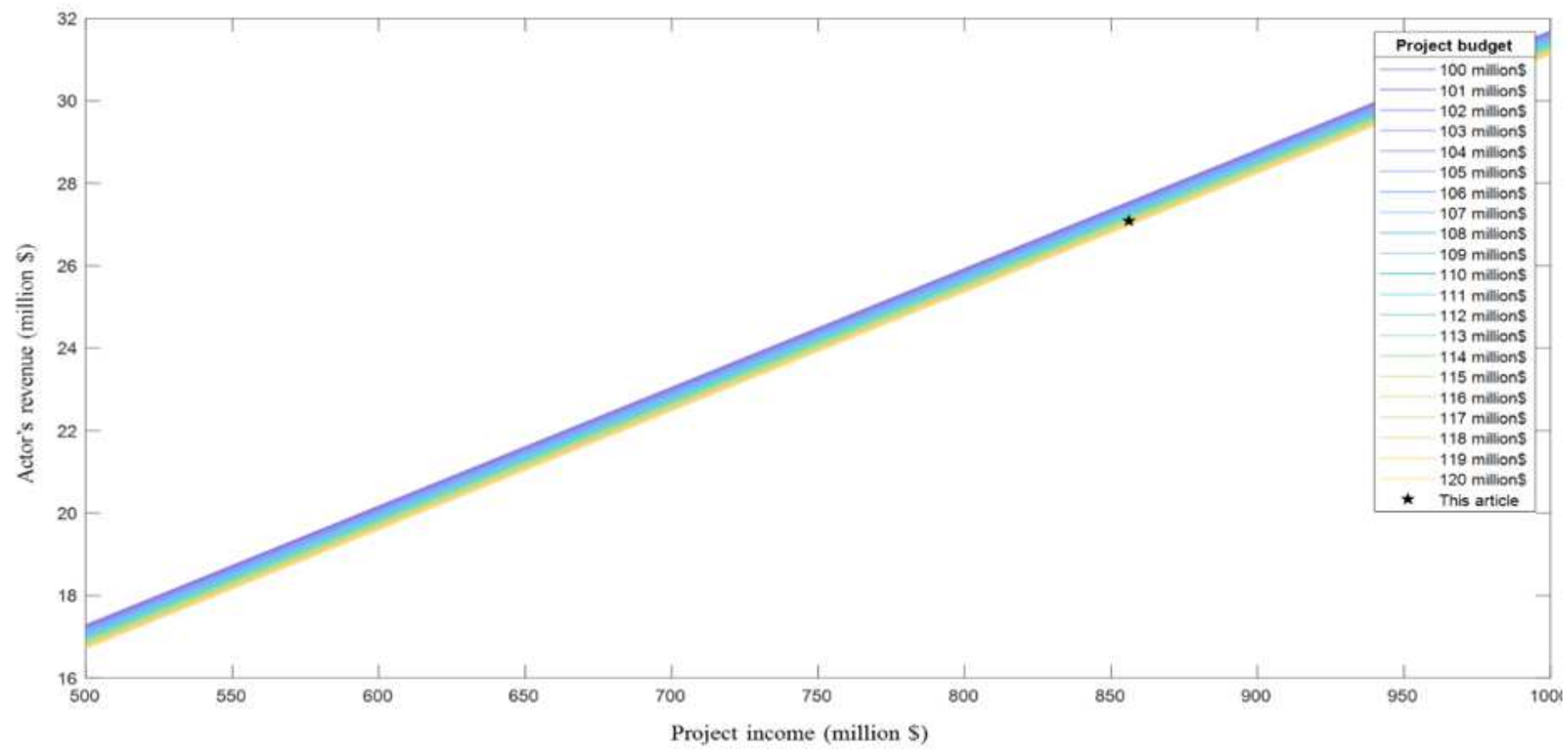

\section{Figure 6}

Actor's revenue dependency on project income

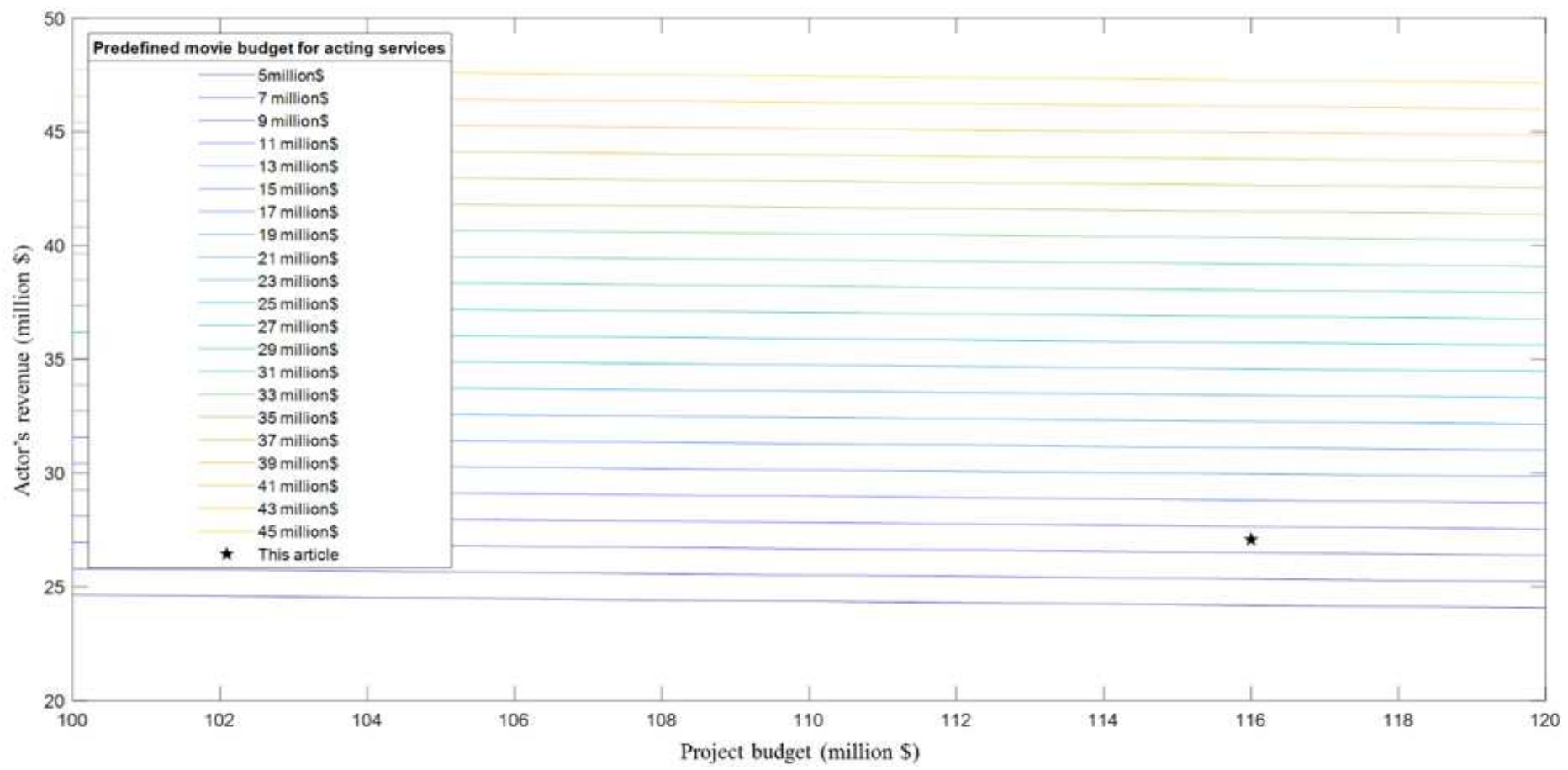

Figure 7 
Actor's revenue dependency on project budget 